Article

\title{
Assessing the Impact of Surface and Upper-Air Observations on the Forecast Skill of the ACCESS Numerical Weather Prediction Model over Australia
}

\author{
Sergei Soldatenko * (1), Chris Tingwell, Peter Steinle and Boris A. Kelly-Gerreyn \\ Australian Bureau of Meteorology, 700 Collins Str., Melbourne, VIC 3008, Australia; \\ chris.tingwell@bom.gov.au (C.T.); peter.steinle@bom.gov.au (P.S.); boris.kelly-gerreyn@bom.gov.au (B.A.K.-G.) \\ * Correspondence: s.soldatenko@bom.gov.au or sergei.soldatenko@bom.gov.au; Tel.: +61-3-9669-4641
}

Received: 15 December 2017; Accepted: 12 January 2018; Published: 16 January 2018

\begin{abstract}
The impact of the Australian Bureau of Meteorology's in situ observations (land and sea surface observations, upper air observations by radiosondes, pilot balloons, wind profilers, and aircraft observations) on the short-term forecast skill provided by the ACCESS (Australian Community Climate and Earth-System Simulator) global numerical weather prediction (NWP) system is evaluated using an adjoint-based method. This technique makes use of the adjoint perturbation forecast model utilized within the $4 \mathrm{D}$-Var assimilation system, and is able to calculate the individual impact of each assimilated observation in a cycling NWP system. The results obtained show that synoptic observations account for about $60 \%$ of the 24 -h forecast error reduction, with the remainder accounted for by aircraft $(12.8 \%)$, radiosondes $(10.5 \%)$, wind profilers $(3.9 \%)$, pilot balloons $(2.8 \%)$, buoys $(1.7 \%)$ and ships $(1.2 \%)$. In contrast, the largest impact per observation is from buoys and aircraft. Overall, all observation types have a positive impact on the 24-h forecast skill. Such results help to support the decision-making process regarding the evolution of the observing network, particularly at the national level. Consequently, this $4 \mathrm{D}$-Var-based approach has great potential as a tool to assist the design and running of an efficient and effective observing network.
\end{abstract}

Keywords: numerical weather prediction; variational data assimilation; adjoint model; sensitivity analysis; forecast sensitivity; observations

\section{Introduction}

Numerical weather prediction (NWP) models are critically reliant on a large number of appropriate quality in situ and remotely sensed observations. These observations provide the data that are needed to accurately define the forecast initial conditions, via the process of data assimilation. Hence, the forecast skill of NWP is substantially influenced by the observations.

To both improve the analysis and increase the forecast skill of NWP systems such as ACCESS [1], the national observing network needs to be regularly evaluated in terms of design and observational types. The significant investment by national meteorological services like the Bureau of Meteorology (from hereon, the Bureau) in national observing networks, and the constant evolution of observational technologies, requires an ongoing assessment of the value of the network components. NWP is one of the major mechanisms for converting observed data into information and services, so an objective measure of the impact of each observation on the quality of short-term forecasts can potentially guide decisions related to network efficiency and effectiveness.

Traditionally, the impact of an observation system, type, or individual instrument on the forecast skill of an NWP system that assimilates it, is assessed by performing an Observing System Experiment (OSE), usually called a Data Denial Experiment (DDE). In an OSE, the forecast skill of two separate runs are compared-one with all observations assimilated and the other with a given observation type 
(or individual instrument) withheld or added (e.g., [2-7]). Any change in forecast skill is attributed to the observations, which have been withheld. The technique can also be used to assess the impact of newly available observations. OSEs can be informative but come with disadvantages: they are computationally expensive and time-consuming to carry out and their results are not especially "fine-grained". They are not suited to evaluate the impact of, say, a single station in an observing network due to the very long duration of the experiment that would be required to produce statistically significant results. For similar reasons, OSEs are not suited to evaluating the impact of assimilating a few extra channels from a multi-channel satellite instrument such as a modern hyper-spectral infra-red sounder because of the length of time required to get statistically significant results. OSEs also only provide information on the dataset that was withheld, and no direct information on the value of other subsets of observations.

A relatively new technique (e.g., [8]), which makes use of the adjoint models utilized within variational assimilation systems, is able to calculate the individual impact that each assimilated observation has in a cycling NWP system-where the impact is typically measured by the reduction in the 24-h forecast error (typically expressed as a total dry or moist energy norm). Such a technique, which uses the same code as four-dimensional data assimilation (4D-Var) systems [9,10], was pioneered by Baker and Daley [11] and Langland and Baker [8], then further explored (e.g., [12-18] and subsequently implemented in a number of NWP centres (e.g., $[5,19,20])$. This $4 \mathrm{D}$-Var approach has the advantage of being able to continually generate and aggregate forecast impacts for all observations, and allows much more fine-grained impact statistics to be generated than is feasible in OSEs. At the UK Met Office, Lorenc and Marriott [20] developed a method of calculating Forecast Sensitivity to Observations (FSO) by means of the technology already used in the Met Office 4D-Var system [21]: specifically, the adjoint perturbation forecast $(\mathrm{PF})$ model which is used in the minimization of the $4 \mathrm{D}$-Var cost function. The development of this capability in the UK Met Office gave rise to the opportunity to implement it in ACCESS, which is built from the Met Office Unified Model [22] and associated $4 \mathrm{D}$-Var software.

The key feature of the adjoint-based FSO lies in the fact that the diagnostic information is generated for all assimilated observations simultaneously - that is, the model does not need to be re-run to examine the impact of each observation type. However, this approach has limitations caused by the linearity of the adjoint model, which limits the lead-time of the forecasts that can be assessed. In addition, the impact of an observation is assessed in the presence of all other observations: this is not the same as measuring the increment in forecast skill caused by adding or withholding the observation from the assimilation. Furthermore, non-assimilated observations, which nevertheless contribute to the skill of an NWP forecast (e.g., the sea surface temperatures which provide some of the boundary condition), are not included. Impact results are also strongly dependent on the choice of the error norm and the spatial domain over which it is calculated.

In this paper, we use FSO capabilities to quantitatively analyze the impact of the Bureau's in situ, non-satellite observations (synoptic, ship weather, radiosonde, wind profiler, moored and drifting buoy and aircraft data) on the short-term $24 \mathrm{~h}$ numerical weather forecasts of the operational global NWP system (ACCESS-G) and its 4D-Var incremental data assimilation system. The impact of the satellite data will be dealt with in a subsequent paper.

The results provide objective guidance to support decisions related to the ongoing management and planning of the Bureau's observing network.

\section{Experiments}

\subsection{Essentials of the Forecast Sensitivity to Observation Method}

The adjoint-based forecast sensitivity method involves the comparison of a $24 \mathrm{~h}$ and a $30 \mathrm{~h}$ forecast provided at the same point in time. The improved skill of the $24 \mathrm{~h}$ forecast compared to the $30 \mathrm{~h}$ forecast is attributed to the observations that were assimilated to produce the $24 \mathrm{~h}$ forecast. Let us 
denote the $24 \mathrm{~h}$ forecasts from an analysis and the background used in the analysis by $\mathbf{x}_{t}^{\mathrm{fa}}$ and $\mathbf{x}_{t}^{\mathrm{fb}}$, respectively, where $\mathbf{x}_{t}^{\mathrm{fb}}$ is identical to a $30 \mathrm{~h}$ forecast from the previous cycle of analysis. Let $\mathbf{x}_{t}^{\mathrm{a}}$ be the verifying analysis at time $t$. In the incremental 4D-Var system used in ACCESS, the adjoint PF model—which has a coarser grid and simpler moist physics than the full field forecast model—is applied. Thus, the forecast errors are calculated with these simplifications. Let $S$ be the operator that reduces the set of cloud moisture variables and interpolates model variables into lower resolution [20]:

$$
\begin{gathered}
\delta \mathbf{w}_{t}^{\mathrm{fa}}=S \mathbf{x}_{t}^{\mathrm{fa}}-S \mathbf{x}_{t}^{\mathrm{a}} \\
\delta \mathbf{w}_{t}^{\mathrm{fb}}=S \mathbf{x}_{t}^{\mathrm{fb}}-S \mathbf{x}_{t}^{\mathrm{a}} \\
\delta \mathbf{w}_{t}=S \mathbf{x}_{t}^{\mathrm{fa}}-S \mathbf{x}_{t}^{\mathrm{fb}}=\delta \mathbf{w}_{t}^{\mathrm{fa}}-\delta \mathbf{w}_{t}^{\mathrm{fb}}
\end{gathered}
$$

where $\delta \mathbf{w}_{t}^{\mathrm{fa}}$ is the error of the forecast started from the analysis; $\delta \mathbf{w}_{t}^{\mathrm{fb}}$ is the error of the forecast started from the background; $\delta \mathbf{w}_{t}$ is the forecast difference.

This technique requires the choice of a suitable metric to measure the change in forecast error. As is standard in the UK Met Office FSO suite (and most others), this metric is the total energy norm calculated as an inner product on the latitude $(\phi)$-longitude $(\lambda)$ spherical grid [20]:

$$
\begin{gathered}
e=\delta \mathbf{w}^{\mathrm{T}} \mathbf{C} \delta \mathbf{w}=\frac{1}{M_{D}} \iiint E r^{2} \cos \phi \mathrm{d} \lambda \mathrm{d} \phi \mathrm{d} r \\
E=\frac{1}{2}\left(\rho u^{\prime 2}+\rho v^{\prime 2}+\frac{\rho g^{2}}{\theta^{2} N^{2}} \theta^{\prime 2}+\frac{1}{\rho c^{2}} p^{\prime 2}+\varepsilon \frac{\rho L^{2}}{c_{p}} q^{\prime 2}\right)
\end{gathered}
$$

where $M_{D}$ is the mass of the atmosphere in the integration domain $D ; r$ is the radial distance; $u, v$ are the zonal and meridional wind components, respectively; $\theta$ is the potential temperature, $p$ is pressure; $q$ is the specific humidity; $c_{p}$ is the heat capacity at constant pressure; $L$ is the latent heat of water vapor condensation; $g$ is the acceleration of gravity; $\rho$ is the air density; $c$ is the speed of sound; $N^{2}$ is the square of the Brunt-Väisälä frequency. The primed variables denote PF model state vector components and the unprimed variables linearization state vector elements. Assuming $\varepsilon=0$ we obtain the dry total energy norm. In the PF model $\varepsilon=1$ meaning that the water vapor can condense releasing its latent heat.

The model provides an option to limit the integration domain in (4), which allows the energy norm to be calculated for the Australian region as well as the global domain. Formally, this option is expressed in the matrix equations by a projection $\mathbf{P}$ that is equal to 1 in the domain of interest and zero outside of this domain. The expression for the change in energy norm in the limited domain can be written as follows [20]:

$$
\delta e \approx\left(\mathbf{M}_{0 \rightarrow t} \mathbf{K} \delta \mathbf{y}\right)^{\mathrm{T}}\left(\frac{\delta e}{\delta \mathbf{w}_{t}}\right)=\delta \mathbf{y}^{\mathrm{T}} \mathbf{K}^{\mathrm{T}} \mathbf{M}_{0 \rightarrow t}^{\mathrm{T}} \mathbf{P}^{\mathrm{T}} \mathbf{C} \mathbf{P}\left(\delta \mathbf{w}_{t}^{\mathrm{fa}}+\delta \mathbf{w}_{t}^{\mathrm{fb}}\right) \approx \delta \mathbf{y}^{\mathrm{T}}\left(\frac{\delta e}{\delta \mathbf{y}}\right)
$$

Here $\mathbf{M}_{0 \rightarrow t}$ is the PF model used to calculate perturbation forecast from the initial time 0 to time $t$; $\mathbf{K}$ is the gain matrix calculated by incremental $4 \mathrm{D}$-Var scheme; $\delta \mathbf{y}=\mathbf{y}^{\mathbf{o}}-H\left(\mathbf{x}^{\mathrm{b}}\right)$ are the observation innovations, where $\mathbf{y}^{\mathrm{o}}$ is the observation vector, $H$ is the observation operator, and $\mathbf{x}^{\mathrm{b}}$ is the background model state. A superscript $\mathrm{T}$ denotes the transpose operation. Therefore, $\mathbf{K}^{\mathrm{T}}$ and $\mathbf{M}_{0 \rightarrow t}^{\mathrm{T}}$ represent the adjoint data assimilation scheme and the adjoint PF model, respectively.

Note that $(\delta e / \delta \mathbf{y})$ is the vector of finite observation sensitivities, the components of which correspond to forecast sensitivity with respect to each observation in $\delta \mathbf{y}$. The influence of $k$ th observation type on the forecast is given by $\delta e_{k} \approx \delta y_{k}(\delta e / \delta \mathbf{y})_{k}$ in units of $\mathrm{J} \cdot \mathrm{kg}^{-1}$. The calculation of FSO is represented schematically in Figure 1. 


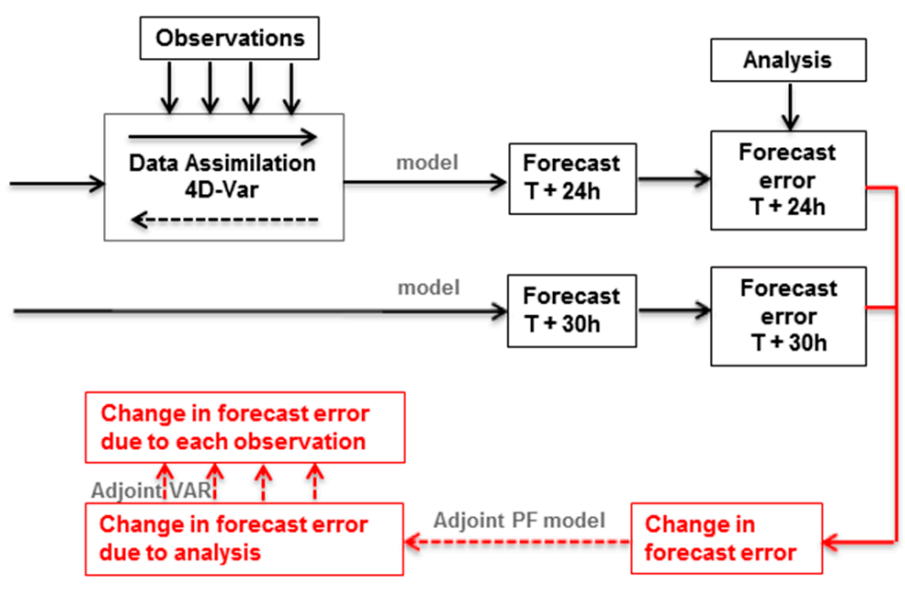

Figure 1. Schematic representation of the adjoint calculation (adapted from [23]).

\subsection{Experimental Design}

The Bureau's operational global NWP system within the overall APS-2 (Australian Parallel Suite version 2) NWP suite, is used for these calculations [24]. The horizontal resolution of the nonlinear forecast model is N512 (1024 $\times 769$ grid points along longitude and latitude, respectively, with the average distance between grid points about $25 \mathrm{~km}$ ), with 70 vertical levels up to $\sim 80 \mathrm{~km}$ altitude. The linear PF includes simplified moist physics and has the same vertical resolution as the nonlinear model with a horizontal resolution of N216 (about $60 \mathrm{~km}$ ). The analyses (initial conditions for the NWP model) are generated by means of the $4 \mathrm{D}-$ Var system with a 6-h assimilation window. Observation impacts represent an estimate of the change in a $24-\mathrm{h}$ forecast error as a consequence of the assimilation of observations. Forecast error is measured in terms of a moist energy norm calculated from the surface to the $150 \mathrm{hPa}$ level over the Australian region (see Figure 2). The adjoint-based observation impacts are calculated from 00Z 1 September 2015 to 00Z 31 December 2016 in 6-h intervals. The experiment details are summarized in Table 1.

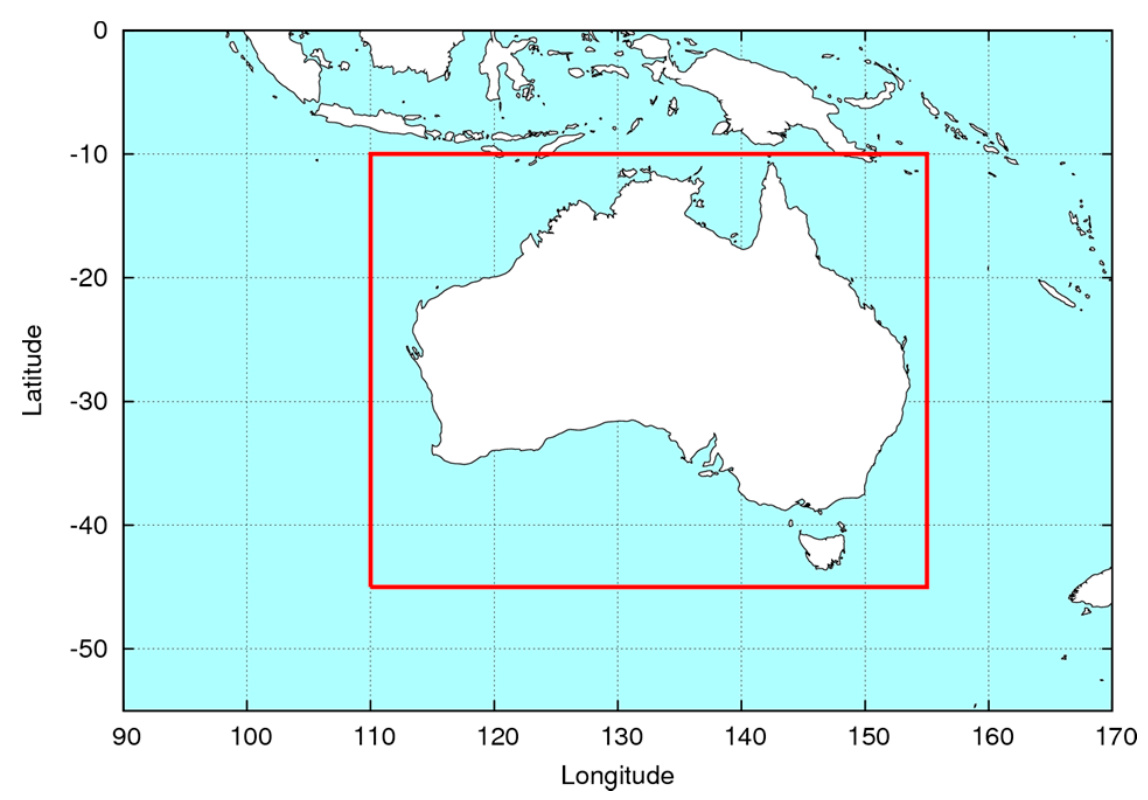

Figure 2. Horizontal domain of the Australian region error norm (red lines). 
For each analysis time, the adjoint FSO system produces an ASCII output file that contains the information on all the observations including satellite and in situ, non-satellite observation types (see Table 2). The following information is contained in the FSO output file:

- Sequential number of observation;

- The observation value;

- The value of innovation (the difference between observation and background values);

- $\quad$ Sensitivity of the forecast to observation;

- $\quad$ Latitude and longitude of observation;

- Pressure level of observation (in $\mathrm{hPa}$ );

- Indicator of the instrument type (radiosonde, surface station, wind profiler);

- Indicator of the observation variable type (temperature, moisture, pressure, horizontal wind components);

- The time offset of the observation from the analysis time;

- Observation error variance;

- $\quad$ WMO (World Meteorological Organization) station identification number;

- $\quad$ Satellite identifier, satellite instrument and channel number.

Table 1. Summary of experiment.

\begin{tabular}{cl}
\hline Data Period & From 00Z 1 September 2015 to 00Z 31 December 2016 \\
\hline Impact Measure & $\begin{array}{l}\text { 24-h forecast error reduction on the moist energy norm calculated from the surface } \\
\text { to } 150 \mathrm{hPa} \text { level over the Australian region. }\end{array}$ \\
\hline NWP System & $\begin{array}{l}\text { Operational version of the Bureau of Meteorology NWP system, APS-2, with the } \\
\text { resolution of N512 for the forecasting model and N216 for the inner loop of 4D-Var, } \\
\text { in horizontal, and 70 levels in vertical. The adjoint of PF includes the moist physics. }\end{array}$ \\
\hline
\end{tabular}

Table 2. Summary of the observation types and the parameters used in this study. The meanings of the symbols in the third columns are as follows: $T$ : temperature; $u$ : zonal wind; $v$ : meridional wind; $p_{s}$ : surface pressure; $R h$ : relative humidity.

\begin{tabular}{crc}
\hline Data ID & Data Type & Information \\
\hline SYNOP & Surface observations from land-based weather stations & $T, u, v, R h, p_{s}$ \\
SHIP & Surface observations from ships and oil rigs & $T, u, v, R h, p_{s}$ \\
TEMP & Upper air observations by radiosondes & $T, u, v, R h, p_{s}$ \\
PILOT & Upper air observations by radiosondes or pilot balloons released from land stations & $u, v$ \\
WINPRO & Upper air wind profile observations & $u, v$ \\
Aircraft & Aircraft observations & $T, u, v$ \\
BUOY & Sea surface observations from drifting and moored buoys & $T, p_{s}$ \\
\hline
\end{tabular}

Calculation of the observation impact is a multi-step process. At each analysis time, the FSO output file is processed into a set of JSON (Java Script Object Notation) files, from which a set of Python-based tools aggregate the individual forecast sensitivities on the basis of observation type and/or station and statistically analyze and visualize the results.

\section{Results}

\subsection{Observation Impacts of the Australian Sonde Network}

Of particular interest to this study, is the relative value of the radiosonde stations located at Maquarie Island, Cocos Island and the three Antarctic stations (Mawson, Casey and Davis), since the operation of these stations requires considerable resources.

There are 34 upper air-observing stations in the Australian network (Figure 3). The contribution of each of these radiosonde stations to the reduction of the forecast error is shown in Table 3. The most 
significant contribution to the forecast quality is provided by the more remote stations Casey, Davis and Mawson in the Antarctic, and Macquarie Island. These stations are shown in red in Figure 3. Upper air stations with the least impact on forecast skill are Moree, Townsville, Cobar, Williamstown, Mount Gambier, Rockhampton, Ceduna, Wagga Wagga and Sydney. These stations are displayed in blue in Figure 3. The analysis of spatial distribution of impacts on the mainland shows that remoter stations are more influential on forecast skill than others. It is also worth noting the high relative impact of remote stations which sample the Southern Ocean (e.g., the Antarctic stations) in comparison to the remote Indian Ocean station on the Cocos Islands. We interpret this as indicating that assimilated information from upstream stations is more likely to propagate into the verification region and beneficially impact the forecast and is consistent with the spatial distribution of impacts from drifting buoys reported in Section 3.4.

Table 3. Australian upper air sonde stations in average rank order with respect to total impact.

\begin{tabular}{|c|c|c|c|c|c|}
\hline Rank & & Station & Latitude (S) & Longitude (E) & Relative Impact \\
\hline 1 & 89611 & Casey (Antarctic) & $66^{\circ} 17^{\prime}$ & $110^{\circ} 31^{\prime}$ & 1.00 \\
\hline 2 & 89571 & Davis (Antarctic) & $68^{\circ} 34^{\prime}$ & $77^{\circ} 58^{\prime}$ & 0.95 \\
\hline 3 & 89564 & Mawson (Antarctic) & $67^{\circ} 36^{\prime}$ & $62^{\circ} 52^{\prime}$ & 0.94 \\
\hline 4 & 94998 & Macquarie Island & $54^{\circ} 30^{\prime}$ & $158^{\circ} 57^{\prime}$ & 0.83 \\
\hline 5 & 94120 & Darwin & $12^{\circ} 25^{\prime}$ & $130^{\circ} 53^{\prime}$ & 0.69 \\
\hline 6 & 94461 & Giles Met Office & $25^{\circ} 02^{\prime}$ & $128^{\circ} 17^{\prime}$ & 0.69 \\
\hline 7 & 94975 & Hobart & $42^{\circ} 50^{\prime}$ & $147^{\circ} 30^{\prime}$ & 0.52 \\
\hline 8 & 94299 & Willis Island & $16^{\circ} 18^{\prime}$ & $149^{\circ} 59^{\prime}$ & 0.49 \\
\hline 9 & 94203 & Broome Airport & $17^{\circ} 57^{\prime}$ & $122^{\circ} 14^{\prime}$ & 0.45 \\
\hline 10 & 96996 & Cocos Island & $12^{\circ} 11^{\prime}$ & $96^{\circ} 50^{\prime}$ & 0.45 \\
\hline 11 & 94659 & Woomera Aero & $31^{\circ} 09^{\prime}$ & $136^{\circ} 49^{\prime}$ & 0.41 \\
\hline 12 & 94326 & Alice Spring & $23^{\circ} 48^{\prime}$ & $133^{\circ} 53^{\prime}$ & 0.39 \\
\hline 13 & 94995 & Lord Howe Island & $31^{\circ} 32^{\prime}$ & $159^{\circ} 04^{\prime}$ & 0.38 \\
\hline 14 & 94150 & Gove Aero & $12^{\circ} 17^{\prime}$ & $136^{\circ} 49^{\prime}$ & 0.37 \\
\hline 15 & 94302 & Learmonth Aero & $22^{\circ} 14^{\prime}$ & $114^{\circ} 05^{\prime}$ & 0.32 \\
\hline 16 & 94170 & Weipa Aero & $12^{\circ} 41^{\prime}$ & $141^{\circ} 55^{\prime}$ & 0.28 \\
\hline 17 & 94610 & Perth Aero & $31^{\circ} 56^{\prime}$ & $115^{\circ} 58^{\prime}$ & 0.25 \\
\hline 18 & 94510 & Charleville Aero & $26^{\circ} 25^{\prime}$ & $146^{\circ} 16^{\prime}$ & 0.25 \\
\hline 19 & 94672 & Adelaide & $34^{\circ} 57^{\prime}$ & $138^{\circ} 32^{\prime}$ & 0.25 \\
\hline 20 & 94637 & Kalgoorlie-Boulder & $30^{\circ} 47^{\prime}$ & $121^{\circ} 27^{\prime}$ & 0.21 \\
\hline 21 & 94638 & Esperance & $33^{\circ} 50^{\prime}$ & $121^{\circ} 53^{\prime}$ & 0.19 \\
\hline 22 & 94802 & Albany Aero & $34^{\circ} 56^{\prime}$ & $117^{\circ} 48^{\prime}$ & 0.18 \\
\hline 23 & 94312 & Port Hedland Aero & $20^{\circ} 22^{\prime}$ & $118^{\circ} 38^{\prime}$ & 0.17 \\
\hline 24 & 94430 & Meekatharra Aero & $26^{\circ} 37^{\prime}$ & $118^{\circ} 33^{\prime}$ & 0.15 \\
\hline 25 & 94866 & Melbourne & $37^{\circ} 40^{\prime}$ & $144^{\circ} 51^{\prime}$ & 0.13 \\
\hline 26 & 94527 & Moree Aero & $29^{\circ} 29^{\prime}$ & $149^{\circ} 50^{\prime}$ & 0.10 \\
\hline 27 & 94294 & Townsville & $19^{\circ} 15^{\prime}$ & $146^{\circ} 46^{\prime}$ & 0.10 \\
\hline 28 & 94711 & Cobar Mo & $31^{\circ} 29^{\prime}$ & $145^{\circ} 50^{\prime}$ & 0.10 \\
\hline 29 & 94776 & Williamstown & $32^{\circ} 48^{\prime}$ & $151^{\circ} 50^{\prime}$ & 0.10 \\
\hline 30 & 94821 & Mount Gambier Aero & $37^{\circ} 44^{\prime}$ & $140^{\circ} 47^{\prime}$ & 0.10 \\
\hline 31 & 94374 & Rockhampton Aero & $23^{\circ} 23^{\prime}$ & $150^{\circ} 29^{\prime}$ & 0.07 \\
\hline 32 & 94653 & Ceduna & $32^{\circ} 08^{\prime}$ & $133^{\circ} 42^{\prime}$ & 0.07 \\
\hline 33 & 94910 & Wagga Wagga & $35^{\circ} 10^{\prime}$ & $147^{\circ} 27^{\prime}$ & 0.04 \\
\hline 34 & 94767 & Sydney & $33^{\circ} 56^{\prime}$ & $151^{\circ} 10^{\prime}$ & 0.01 \\
\hline
\end{tabular}




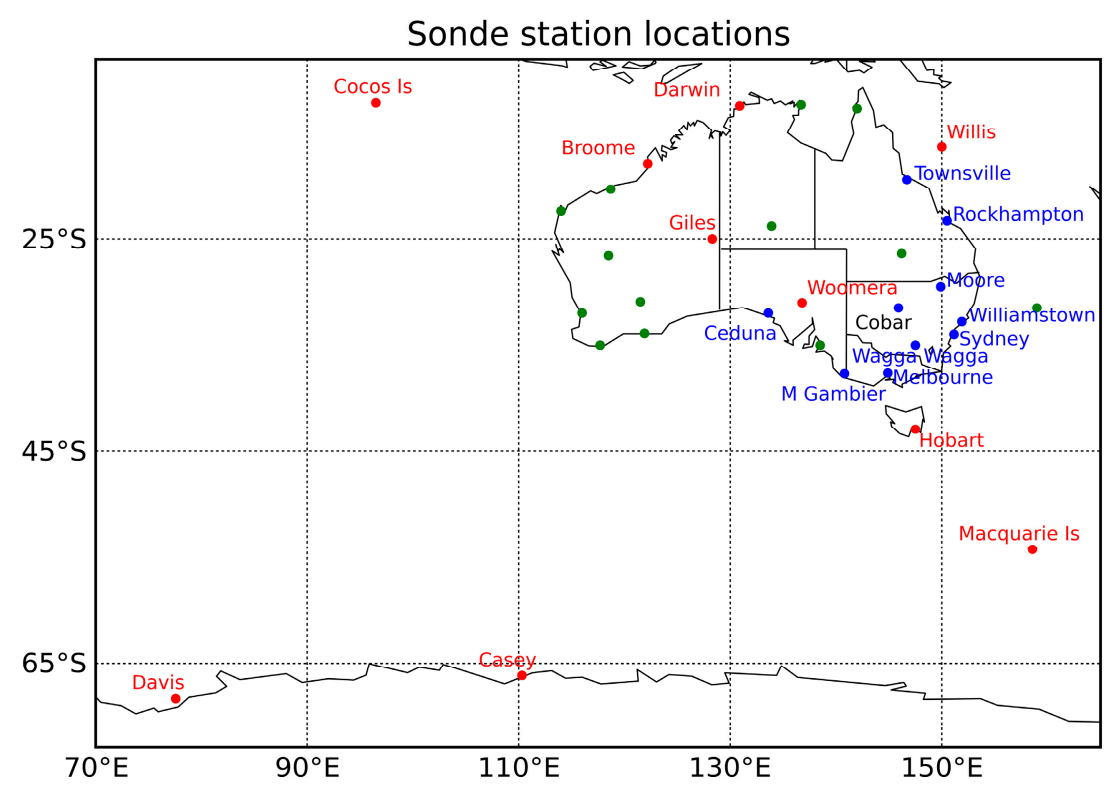

Figure 3. The Australian upper air-observing network (the most influential stations are shown in red, stations with the least impact are displayed in blue, the remaining stations are shown in green). (Mawson station is outside the domain shown).

\subsection{Observation Impacts of Australian Wind Profilers}

Wind profilers are radar weather observing instruments that continually measure wind speed and direction in the upper air at different levels above the ground using radio waves.

During the study period, the Australian wind profiler network included 11 operational profilers (Figure 4) supplied by ATRAD Pty. Ltd. (Adelaide, Australia) [25]. Eight profilers are boundary-layer measurement devices and three profilers measure wind in the troposphere and lower stratosphere. The new profilers in Longreach and Mackay are also tropospheric-stratospheric profilers, however, they were not yet operational during the study period. The profilers at Launceston and Carnarvon were not assimilated during the bulk of the study period due to quality control settings supplied by the Met Office and are thus not included here. All Australian operational profilers operate at a frequency of $55 \mathrm{MHz}$, providing winds from $500 \mathrm{~m}$ to $20 \mathrm{~km}$ (Stratospheric-Tropospheric profilers), and from $300 \mathrm{~m}$ to $7 \mathrm{~km}$ (Boundary Layer profilers). Operational profilers produce a wind estimate every 2-6 min, depending on mode of operation. These data are then quality controlled and averaged to produce wind estimates every $30 \mathrm{~min}$. The wind profile data are then sent to the Bureau in BUFR (Binary Universal Form for the Representation of meteorological data) format [26].

Figure 5 shows the total impacts and the impact per observation calculated for the Australian summer (December 2015-February 2016). The results calculated for the Australian winter (June-August 2016) are shown in Figure 6. In these figures stations are ranked in descending order of their impact on the $24 \mathrm{~h}$ forecast skill. Observations from wind profilers located at Halls Creek, Tennant Creek, Ceduna and Cairns yield the largest contributions to the forecast error reduction. Contributions of these wind profilers differ only slightly. In contrast, observations from wind profilers located at Canberra, Sydney and East Sale contribute 3-4 times less to the forecast error reduction.

In general, profilers located in northern Australia have a greater impact (in terms of the forecast error reduction) than profilers situated in the southern part of the Australian continent. This north-south difference may arise from the fact that the number of observations from the northern profilers is considerably larger than the number of observations from the southern profilers (Figure 7)-the southern (older) stations report observations less frequently than the northern stations. This also may explain why the observation data in the layer between 850 and $500 \mathrm{hPa}$ pressure levels contribute the most to the reduction of the forecast error (Figures $5 \mathrm{a}$ and $6 \mathrm{a}$ ). In contrast, the impact 
per observation is more uniform across the pressure levels (Figures $5 b$ and $6 b$ ) and consequently, data from all levels have a similar impact per observation on the forecast quality.

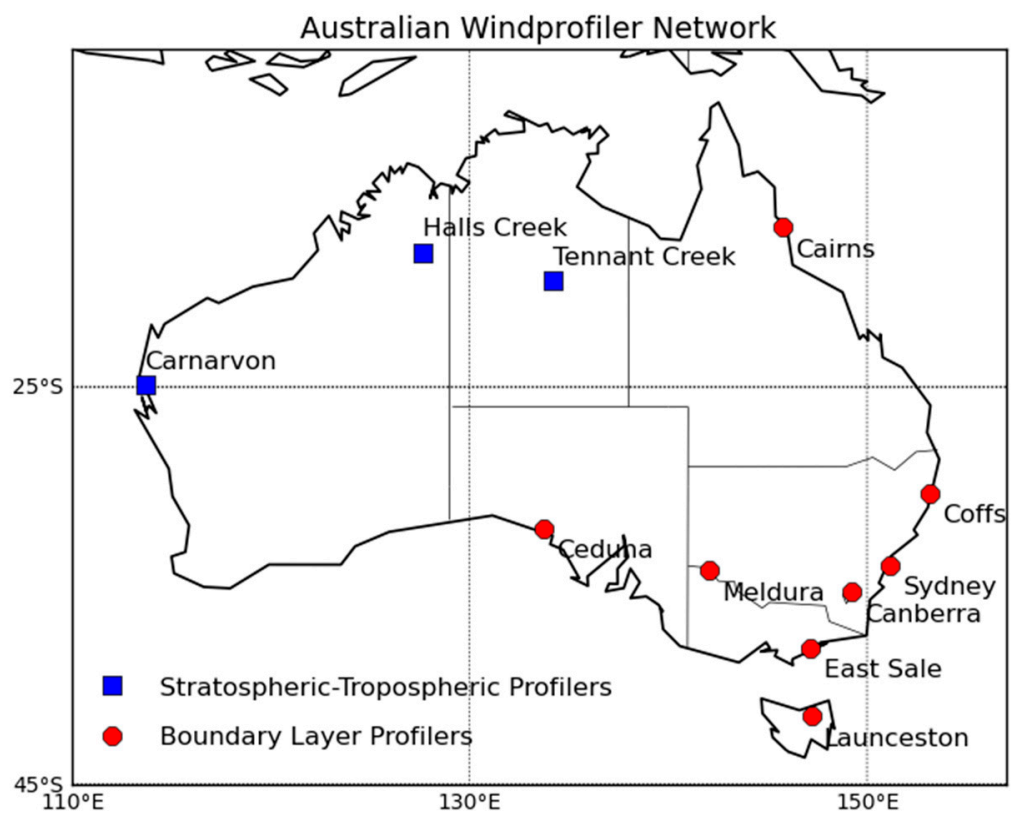

Figure 4. The location of operational Australian wind profilers during this study.

(a)

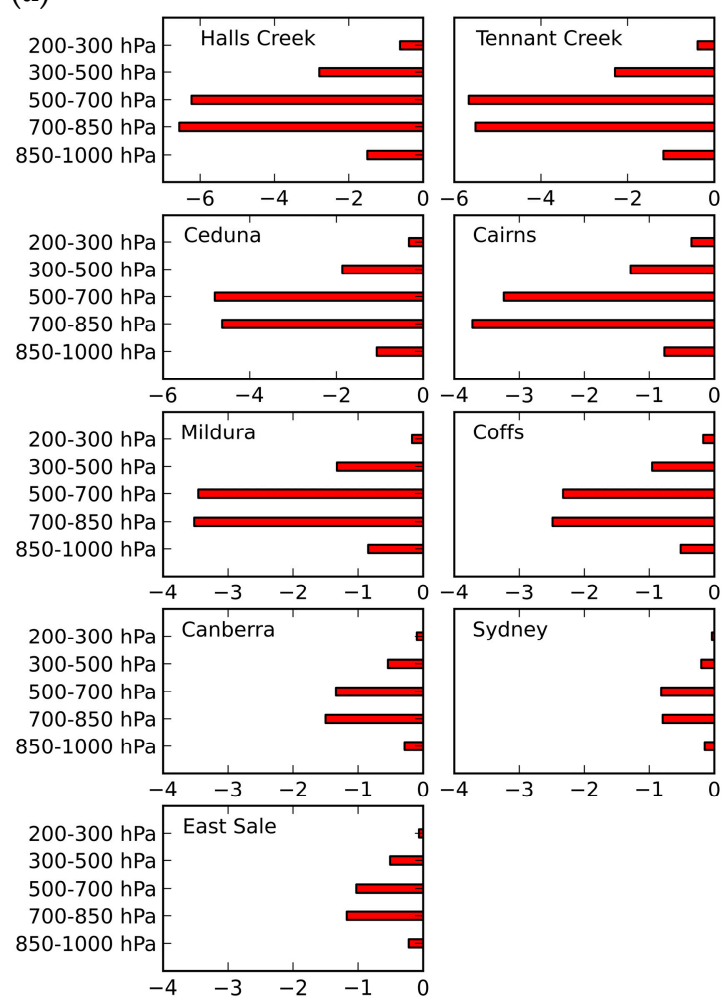

(b)

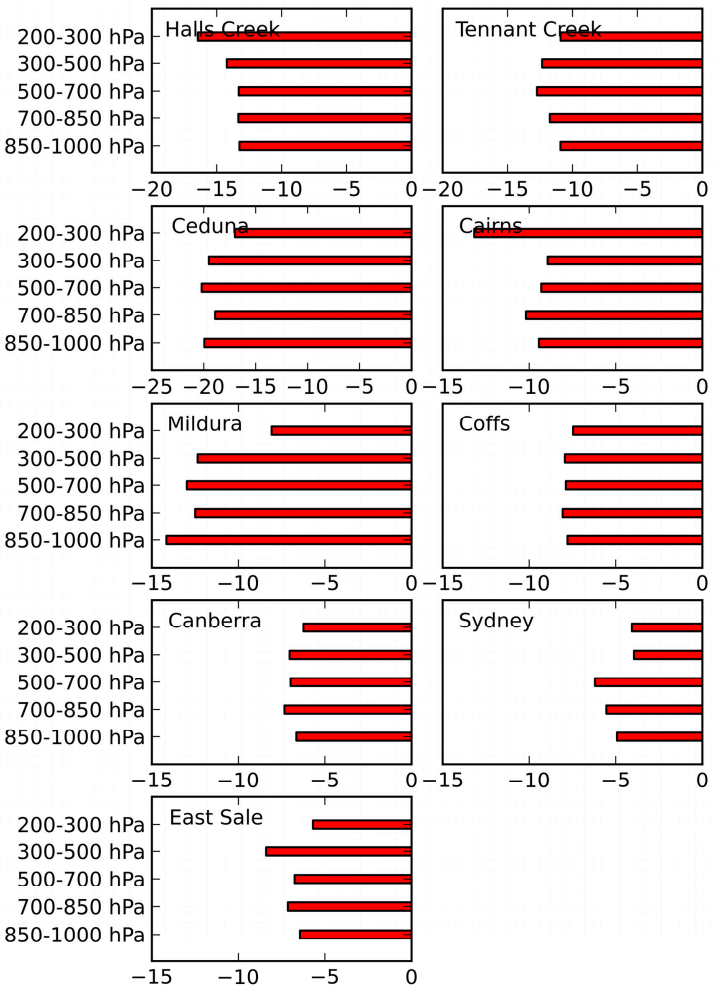

Figure 5. Total impact $\left(\mathrm{J} \mathrm{kg}^{-1}\right)$ (a) and impact per observation $\left(10^{5} \mathrm{~J} \mathrm{~kg}^{-1}\right)$ (b) for the period of December 2015-February 2016. 
(a)

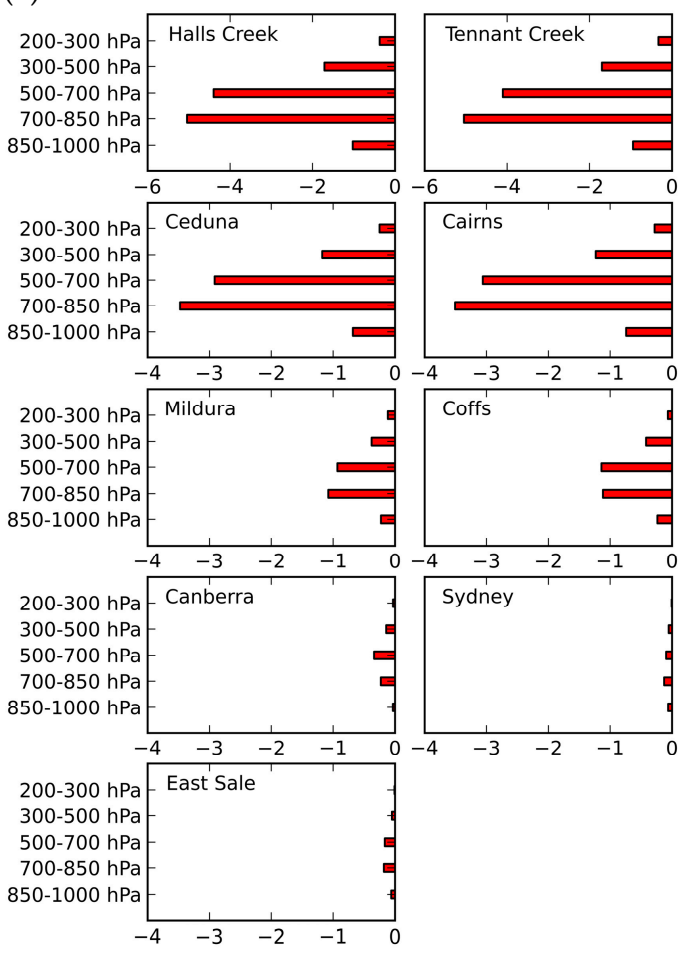

(b)

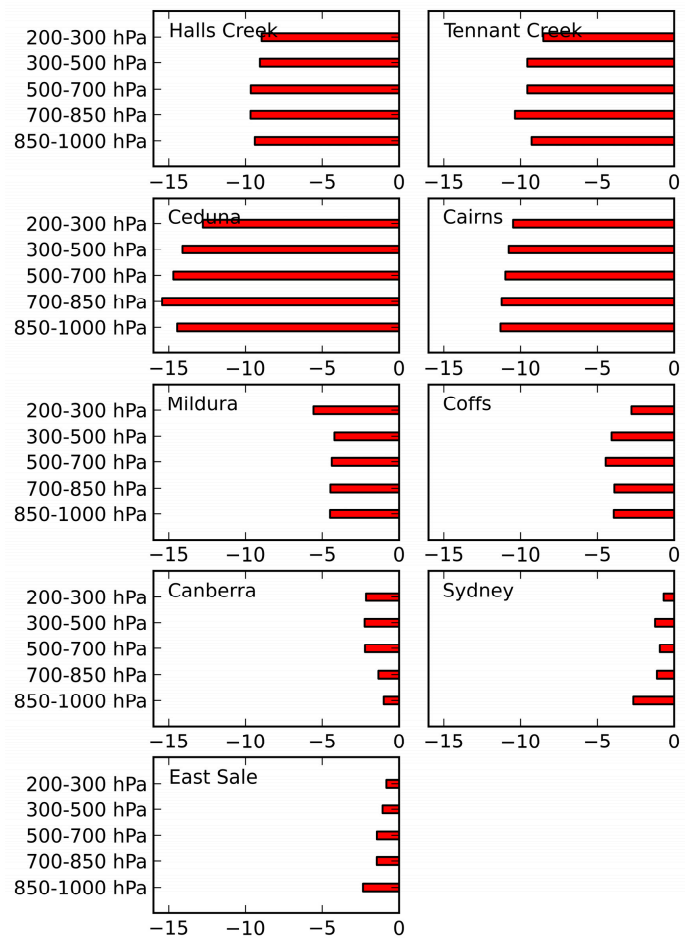

Figure 6. Total impact $\left(\mathrm{J} \mathrm{kg}^{-1}\right)$ (a) and impact per observation $\left(10^{5} \mathrm{~J} \mathrm{~kg}^{-1}\right)(\mathbf{b})$ for the period of June-August 2016.

(a)

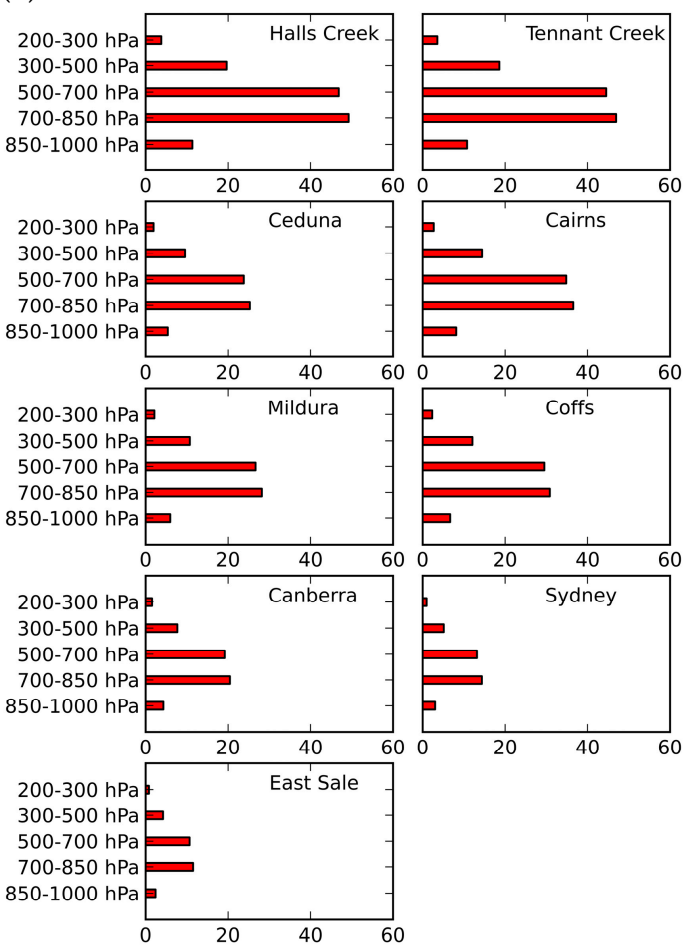

(b)

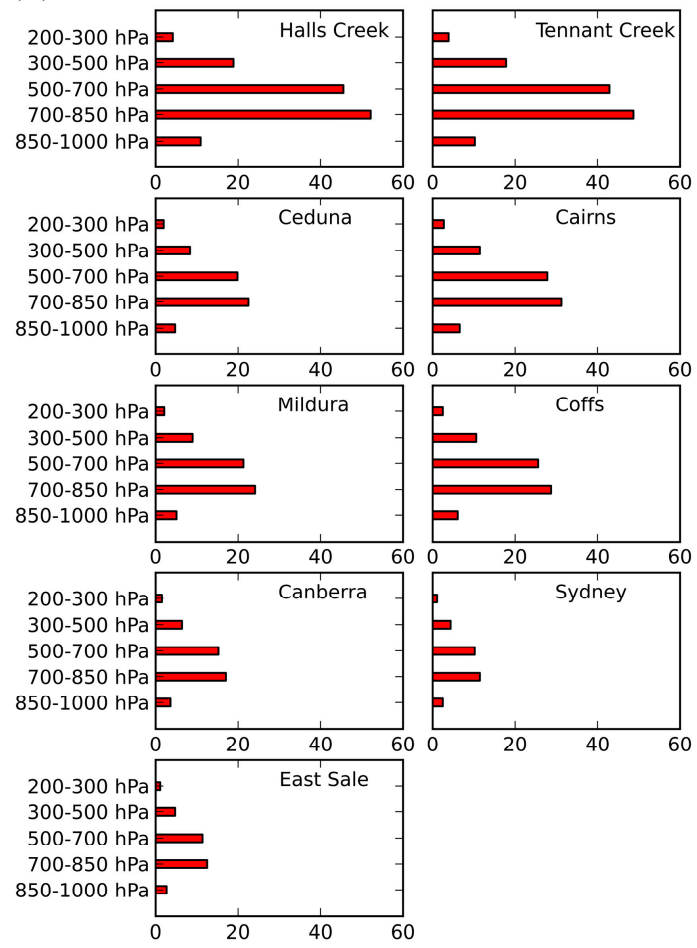

Figure 7. Total number of observations $\left(10^{3}\right)$ for the period of December 2015-February 2016 (a) and June-August 2016 (b). 


\subsection{Observation Impacts of Australian Synoptic Observations}

Surface weather data are obtained from different types of observing stations around Australia, on offshore islands, and in the Antarctic. They include Bureau-staffed observer stations and Bureau-owned automatic weather stations, cooperative observer stations at which manual readings are made. Surface weather observations used in the ACCESS data assimilation system are taken at 756 manned and automated weather stations. However, only 70 percent of them (525 stations) are standard automatic weather stations (AWS) managed by the Bureau. The remaining 231 stations are cooperative stations that are funded by the Bureau but operated by contractors-all but a few of these stations provide only manual readings. Station locations are chosen based on a range of different requirements and constraints, including:

(a) The need for observations of particular types;

(b) How well a location represents the surroundings;

(c) Availability of land, observers (if required) and infrastructure;

(d) The presence of other stations in the area.

The spatial distribution of synoptic stations is not even across the country. The observing network is densest in the most highly populated areas in the country (Sydney, Melbourne, Canberra, Adelaide, Perth, Brisbane, Hobart and Darwin). Generally, the southeastern quadrant of Australia has the densest synoptic observing network. At the majority of locations, AWS send synoptic send data to the Bureau on an hourly basis (although one-minute data is transmitted every minute for core Bureau products and services). However, synoptic observation reports prepared by cooperative stations are typically sent to the Bureau one to two times per day.

The total impacts of synoptic observations from the AWS and cooperative stations for the periods of December 2015-February 2016 and June-August 2016 calculated for four NWP analysis times are illustrated in Figure 8. This figure shows that the impact of observations from AWS exceed the impact of observations from cooperative stations by at least an order of magnitude. This is because the number of observations is considerably different between AWS and cooperative stations.

(a)

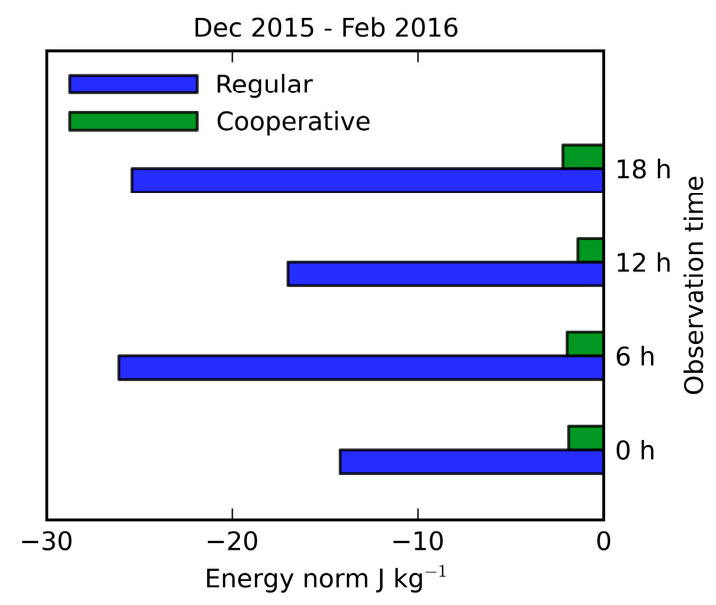

(b)

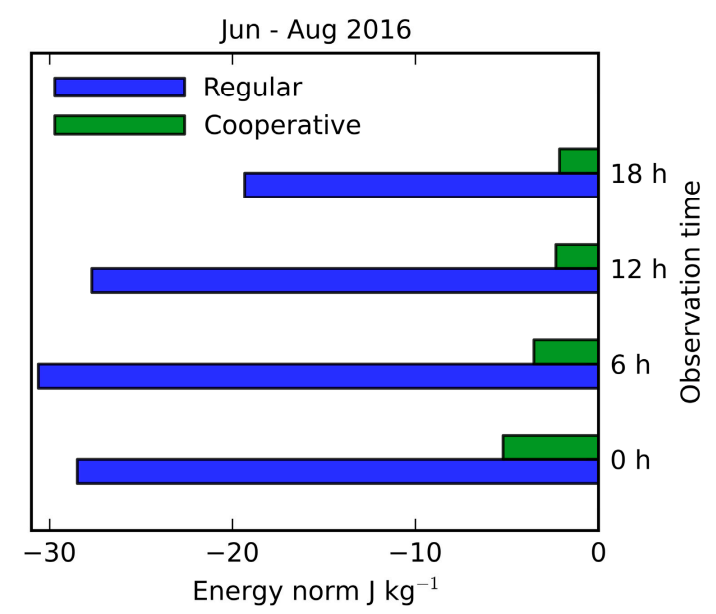

Figure 8. Impact of synoptic observations from AWS (automatic weather station) and cooperative stations for the period of December 2015-February 2016 (a) and June-August 2016 (b).

In the Australian summer (December-February) the total impacts for all four analysis times are less than the impact for the Australian winter (June-August). This difference is most likely due to the fact that the moisture contributes about 33 percent of the total energy [20]. Moisture content in the atmosphere fluctuates from season to season. Typically, an Australian summer season is drier 
than a winter season, thus, the moisture contribution to the total energy norm is larger in winter than in summer. The difference between summer and winter impacts may also be the consequence of the adjoint model properties and limitations (e.g., [27]). Adjoint models are linear models and, therefore, their results are most applicable when the tangent linear approximation is valid. Due to the effects of baroclinic instability, weather fluctuates more intensively in winter than in summer seasons. Therefore, winter trajectories generated by the (nonlinear) NWP model are more oscillating than summer trajectories and, therefore, more sensitive to the initial conditions. In addition, error growth in the adjoint model may be dominated by highly nonlinear moist physics. As a result, observation sensitivities calculated by the adjoint model for a winter season may be slightly larger than for the summer season.

Figure 9 shows the impact of each AWS and cooperative station on the reduction of the forecast error calculated for the southern hemisphere winter season (June-August 2016). The winter season is taken as an example because the effect is the same in summer. In Figure 9 stations are divided into three categories: stations that have on average a positive effect on the forecast quality $(\delta e<0)$, stations with on average a negative effect $(\delta e>0)$ on the forecast skill, and "neutral" stations $(\delta e=0)$. Weather observations, obtained from about 78 percent of both AWS and cooperative stations, are beneficial. Observations taken at about 7 percent of AWS and 17 percent of cooperative stations are neutral. Observations obtained from about 15 percent of AWS and 5 percent of cooperative stations are not beneficial, at least within the framework of the adjoint-based method discussed in Section 2. It appears that the denser the network the lower the impact of individual stations and vice versa. This is consistent with the upper air results.

The reason that some stations have, on average, detrimental impact on forecast skill will be a topic of further investigation. For now, we note that most such stations are only weakly detrimental and that those that are more detrimental tend to be inland and remote. Given that these results are only for two seasons (summer and winter), this suggests that exploring the seasonal variation of surface station impacts, and the possible influence of particular synoptic regimes on observational representativeness errors, may be a useful line of enquiry. Stations that are persistently detrimental can also be investigated for quality control issues.

\subsection{Observation Impacts from Buoys}

A significant source of surface observations in ACCESS are moored and drifting ocean buoys and ships that collect weather data. The latter two sources of data come from both Bureau funded and internationally funded programs. Such marine surface observations are especially important in the Southern Hemisphere, which is geographically dominated by ocean.

Figure 10 shows the average impact per observation for each of the buoys assimilated during the period September to December 2015, for the Australian region error norm; impacts are plotted at the average position of the buoy during the period. Benefical impact is dominated by drifting buoys in the southern Indian Ocean (upstream from the Australian region in the prevailing westerlies), the Southern Ocean and the moored buoys in the western equatorial region of the Pacific Ocean. The substantial impact of buoys far from Australia should be interpreted with caution: only average position is shown and some such buoys will have drifted considerably during the period. In contrast, buoy impacts derived from the global error norm (not shown) are much more evenly distributed across the globe. 
(a)

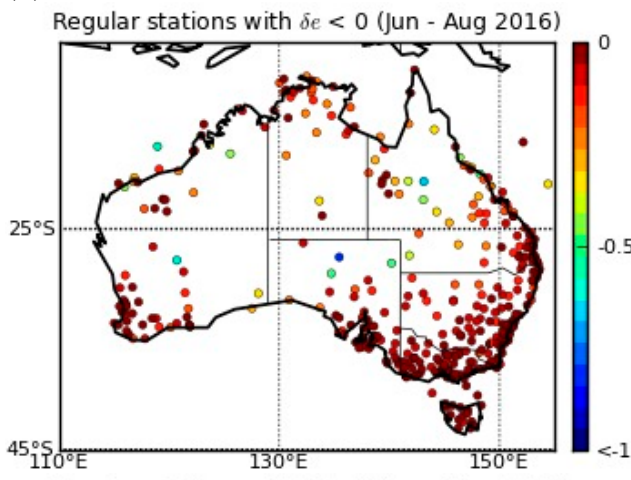

Regular stations with $\delta e>0$ (Jun - Aug 2016)

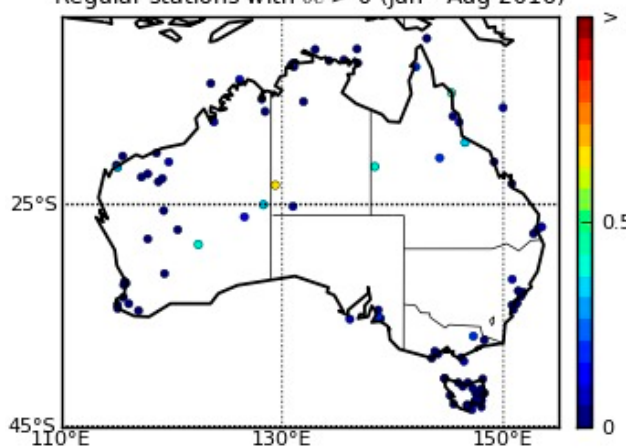

Regular stations with $\delta e=0$ (Jun - Aug 2016)

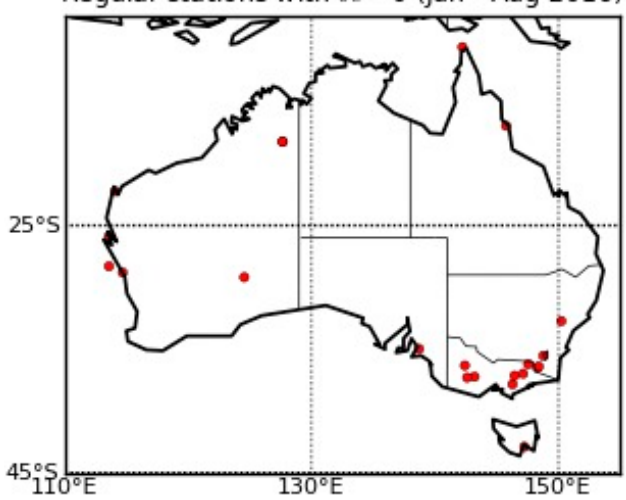

(b)
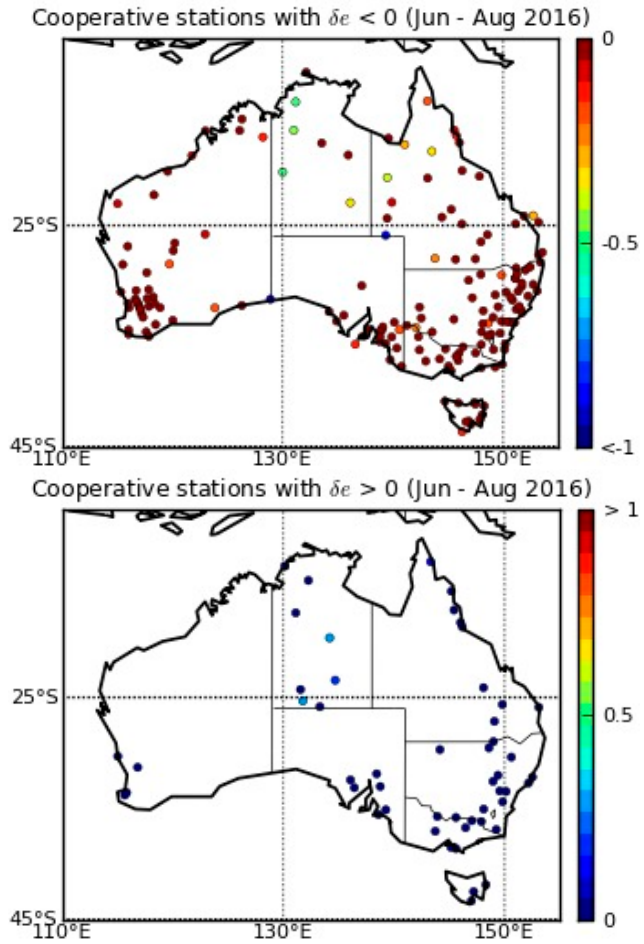

Cooperative stations with $\delta e=0$ (Jun - Aug 2016)

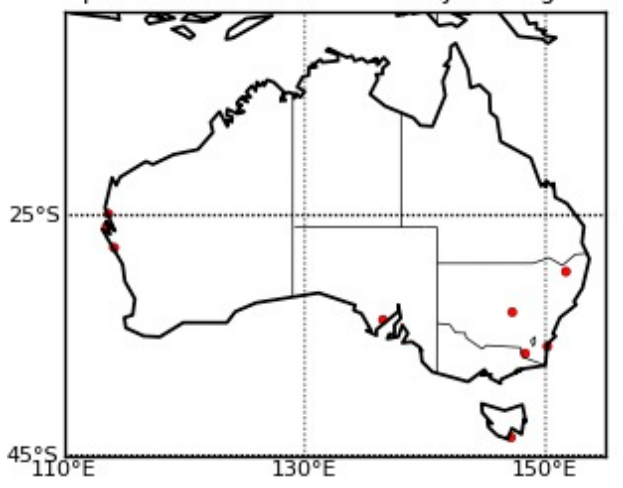

Figure 9. Impact $\left(\mathrm{J} \mathrm{kg}^{-1}\right)$ of AWS (a) and cooperative (b) synoptic observations for winter 2016.

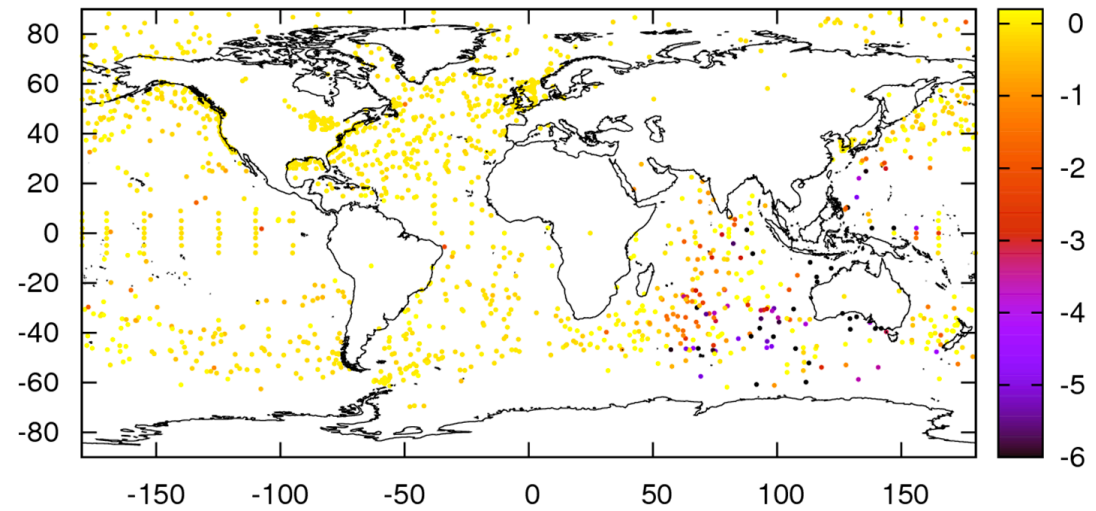

Figure 10. Average impact $\left(10^{-5} \mathrm{~J} \mathrm{~kg}^{-1}\right)$ for the Australian region error norm from individual buoys over the period September to December 2015: the impact is plotted at the average position of the buoy during this period. 


\subsection{Comparison of Observation Impacts of Each In Situ Observation Type}

The total average observation impact per day in the ACCESS system, aggregated by observation type, and the impact per observation for each in situ observation type (Table 2) are shown in Figure 11. Observations of all types reduce the forecast error on average during both winter and summer periods. Synoptic observations from AWS stations yield the largest contribution to the forecast error reduction (Figure 11a). Aircraft and radiosondes rank second and third, respectively, followed by wind profilers and pilot balloons. Recall that these results are obtained for the Australian moist energy norm. For the moist energy norm calculated over the globe, synoptic observations are usually not the major in situ observation type contributors in the forecast error reduction. Typically, radiosondes and aircrafts demonstrate the largest contributions (e.g., $[19,20])$. In contrast, the impact per observation is the largest for buoys (Figure 11b), which is consistent with other studies (e.g., [19]). This is because buoys are the main source of information at the marine boundary layer. Aircraft and synoptic observations rank second and third, followed by ships, radiosondes, pilot balloons and wind profilers.

(a)

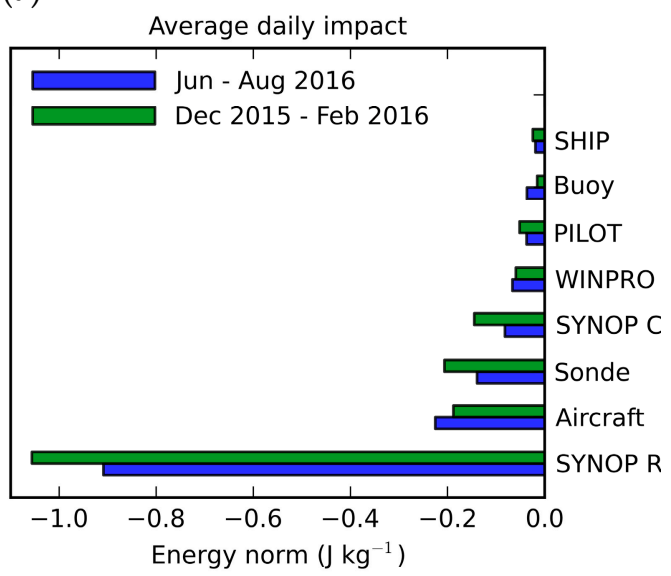

(b)

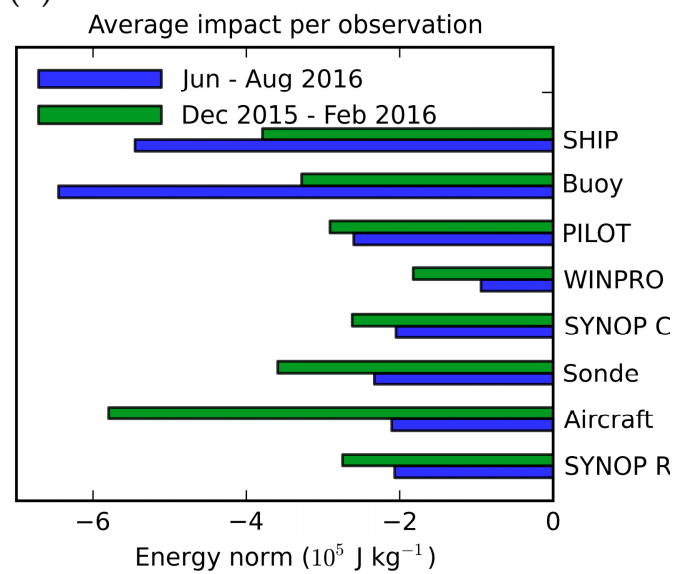

Figure 11. Average daily impact (a) and impact per observation (b) for each non-satellite observation types for the period of December 2015-February 2016 and June-August 2016 (SYNOP R-AWS synoptic stations, SYNOP C-cooperative observer stations).

\section{Discussion and Conclusions}

In this paper, we evaluated impacts of in situ observations (ground and ocean-based synoptic and ship observations, wind profiler information, radiosonde and wind balloon upper air observations, and aircraft data) on 24-h weather forecast error reduction using the adjoint-based FSO approach developed by the Met Office run in conjunction with the operational ACCESS global NWP system. The impact is measured by the reduction in the 24-h forecast error expressed as a moist energy norm calculated in the Australian domain. Results show that synoptic observations account for about $60 \%$ of the $24-\mathrm{h}$ forecast error reduction, with the remainder accounted for by aircraft $(12.8 \%)$, radiosondes $(10.5 \%)$, wind profilers $(3.9 \%)$, pilot balloons $(2.8 \%)$, buoys $(1.7 \%)$ and ships $(1.2 \%)$. In contrast, the largest impact per observation is from buoys and aircraft. The large impact per observation from buoys concurs with other published studies and results from their provision of data from the otherwise poorly sampled surface ocean. Unsurprisingly, the drifting buoys closer to Australia have the larger impact on forecast skill, with buoys in the eastern Indian Ocean and off the southern Australian coast yielding the highest impacts. Indian ocean buoy observations are thus especially valuable for NWP forecast skill over the Australian continent. In terms of total impact per day, data from surface automatic weather stations have the largest impact on the forecast quality over the Australian region, a result that contrasts with global error norm calculations, which show that radiosondes are the most 
impactful in situ observations. This contrast reflects the much shorter forecast error length scales at the surface as compared to the mid-troposphere in typical data assimilation systems [28].

Previous work on quantifying the impact of Australian region rawinsonde observations in the then Bureau global NWP system [29,30] was reported by Seaman [31] using an analysis impact method described earlier [32]. In this, workstations were ranked according to how often they appeared in the top ten of the most influential Australian stations (in the sense of reducing forecast error) over a period from 1994 to 2007. As might be expected, remote stations were found to have more impact than those in the denser parts of the Australian network: in particular stations located in the tropical and sub-tropical north west of the continent were found to have the most impact. The results obtained in this paper show that there does not seem to be a significant dependence of impact on latitude, in contrast with an earlier study by Seaman [32]. This contrast is most likely due to the significant improvements in NWP data assimilation methods in the last two decades. A similar effect has been noted in most data assimilation systems, where short range forecast error variances now only have a weak latitudinal dependence-a much different situation to 10 or 20 years ago. The results obtained allow us to rank the Australian upper air stations with respect to their impacts on the forecast skill and to identify the most influential observations. Upper air radiosonde stations in more remote locations (e.g., Macquarie Island, Antarctic sites) have a greater impact on forecast skill than stations on the mainland.

Similarly, the more densely distributed synoptic sites have less of an impact on forecast skill compared to the more remote locations. Remote stations also tend to be upwind of substantial parts of the Australian mainland which may enhance their impact. In general, wind profilers located in northern Australia have a greater impact (in terms of the forecast error reduction) than profilers situated in the southern part of the Australian continent, a difference attributable to both to the larger number of observations from the northern stations and their remoteness.

Overall, all observation types have a positive impact on the 24-h forecast skill. Such results help to support the decision-making process regarding the evolution of the observing network, particularly at the national level. Consequently, this $4 \mathrm{D}$-Var-based approach can be considered to be a tool for guiding the design and running of an efficient and effective observing network. The results obtained indicate great potential for FSO impact data to guide and inform the planning, assessment and development of Bureau observing networks. Future studies will explore further the seasonal and inter-annual variability of these impacts and also address the impact of satellite observations assimilated by the ACCESS NWP global system.

Acknowledgments: The atmospheric model (UM) and data assimilation (4D-Var) used in the ACCESS NWP suite were developed at the Met Office, as was the FSO software used in this work. The continuing and timely support and advice by Met Office staff is gratefully acknowledged.

Author Contributions: All authors contributed equally in the preparation of this manuscript.

Conflicts of Interest: The authors declare no conflict of interest.

\section{References}

1. Puri, K.; Dietachmayer, G.; Steinle, P.; Dix, M.; Rikus, L.; Logan, L.; Naughton, M.; Tingwell, C.; Xiao, Y.; Barras, V.; et al. Implementation of the initial ACCESS numerical weather prediction system. Aust. Meteorol. Oceanogr. J. 2013, 63, 265-284. [CrossRef]

2. Kelly, G.; Thépaut, J.-N. Evaluation of the impact of the space component of the Global Observing System through Observing System Experiments. ECMWF Newsl. 2007, 113, 16-28.

3. Kelly, G.; Bauer, P.; Geer, A.J.; Lopez, P.; Thépaut, J.-N. Impact of SSM/I observations related to moisture, clouds and precipitation on global NWP forecast skill. Mon. Weather Rev. 2007, 136, 2713-2726. [CrossRef]

4. Marseille, G.J.; Stoffelen, A.; Barkmeijer, J. Sensitivity Observing System Experiment (SOSE)—A new effective NWP-based tool in designing the global observing system. Tellus A 2008, 60, 216-233. [CrossRef]

5. Gelaro, R.; Zhu, Y. Examination of observation impacts derived from observing system experiments (OSEs) and adjoint models. Tellus A 2009, 61, 179-193. [CrossRef] 
6. Bauer, P.; Radnóti, G. Study on Observing System Experiments (OSEs) for the Evaluation of Degraded EPS/Post-EPS Instrument Scenarios; Report Available from ECMWF; ECMWF: Reading, UK, 2009; p. 99.

7. Masutani, M.; Schlatter, T.W.; Erico, R.M.; Stoffen, A.; Andersson, E.; Lahoz, W.; Woollen, J.S.; Emmitt, G.D.; Riishøjgaard, L.-P.; Lord, S.J. Observing System Simulation Experiments. In Data Assimilation; Lahoz, W., Khattatov, B., Menard, R., Eds.; Springer: Berlin/Heidelberg, Germany, 2010; pp. 647-679.

8. Langland, R.H.; Baker, N.L. Estimation of observation impact using the NRL atmospheric variational data assimilation adjoint system. Tellus A 2004, 56, 189-201. [CrossRef]

9. Le Dimet, F.-X.; Talagrand, O. Variational algorithms for analysis and assimilation of meteorological observations: Theoretical aspects. Tellus 1986, 38A, 97-110. [CrossRef]

10. Courtier, P.; Thepaut, J.-N.; Hollingsworth, A. A strategy for operational implementation of 4D-Var, using an incremental approach. Q. J. R. Meteorol. Soc. 1994, 120, 1367-1387. [CrossRef]

11. Baker, N.; Daley, R. Observation and background adjoint sensitivity in the adaptive observation targeting problem. Q. J. R. Meteorol. Soc. 2000, 126, 1434-1454. [CrossRef]

12. Errico, M.R. Interpretations of an adjoint-derived observational impact measure. Tellus A 2007, 59, $273-276$. [CrossRef]

13. Daescu, D.N. On the deterministic observation impact guidance: A geometrical perspective. Mon. Weather Rev. 2009, 137, 3567-3574. [CrossRef]

14. Daescu, D.N. On the sensitivity equations of four-dimensional variational (4D-Var) data assimilation. Mon. Weather Rev. 2008, 136, 3050-3065. [CrossRef]

15. Daescu, D.N.; Todling, R. Adjoint estimation of the variation in a model functional output due to assimilation of data. Mon. Weather Rev. 2009, 137, 1705-1716. [CrossRef]

16. Sandu, A.; Daescu, D.N.; Carmichael, G.R.; Chai, T. Adjoint sensitivity analysis of regional air quality models. J. Comput. Phys. 2005, 204, 222-252. [CrossRef]

17. Tremolet, Y. Computation of observation sensitivity and observation impact in incremental variational data assimilation. Tellus A 2008, 60A, 964-978. [CrossRef]

18. Cioaca, A.; Sandu, A.; de Sturler, E. Efficient methods for computing observation impact in $4 \mathrm{D}-$ Var data assimilation. Comput. Geosci. 2013, 17, 975-990. [CrossRef]

19. Cardinali, C. Monitoring the observation impact on the short-range forecast. Q. J. R. Meteorol. Soc. 2009, 135, 239-250. [CrossRef]

20. Lorenc, A.C.; Marriott, R.T. Forecast sensitivity to observations in the Met Office Global numerical weather prediction system. Q. J. R. Meteorol. Soc. 2014, 140, 209-224. [CrossRef]

21. Rawlins, F.; Ballard, S.P.; Bovis, K.J.; Clayton, A.M.; Li, D.; Inverarity, G.W.; Lorenc, A.C.; Payne, T.J. The Met Office global 4-dimensional data assimilation system. Q. J. R. Meteorol. Soc. 2007, 133, 347-362. [CrossRef]

22. Walters, D.; Boutle, I.; Brooks, M.; Melvin, T.; Stratton, R.; Vosper, S.; Wells, H.; Williams, K.; Wood, N.; Allen, T.; et al. The Met Office Unified Model Global Atmosphere 6.0/6.1 and JULES Global Land 6.0/6.1 configurations. Geosci. Model Dev. 2017, 10, 1487-1520. [CrossRef]

23. Auligné, T.; Xiao, Q. Adjoint Sensitivity and Observation Impact. UCAR 2009. Available online: http:/ / www2. mmm.ucar.edu/wrf/users/workshops/WS2009/presentations/2A-05.pdf (accessed on 12 April 2017).

24. BNOC Operational Bulletin No. 105, 16 March 2016: “APS2 Upgrade to the ACCESS-G Numerical Weather Prediction System". Available online: http:/ / www.bom.gov.au/australia/charts/bulletins/APOB105.pdf (accessed on 1 June 2017).

25. Dolman, B.; Reid, I.; Kane, T. The Australian Wind Profiler Network. In Proceedings of the WMO Technical Conference on Meteorological and Environmental Instruments and Methods of Observation (CIMO TECO 2016), Madrid, Spain, 27-30 September 2016.

26. World Meteorological Organisation (WMO). Manual on Codes International Codes Volume I.2 Annex II to the WMO Technical Regulations Part B-Binary Codes. 2016. Available online: https:/ /library.wmo.int/ opac/doc_num.php?explnum_id=3421 (accessed on 7 December 2017).

27. Errico, M.R. What is an adjoint model? Bull. Am. Met. Soc. 1997, 78, 2577-2591. [CrossRef]

28. Ingleby, N.B. The statistical structure of forecast errors and its representation in the Met Office global three-dimensional variational data assimilation system. Q. J. R. Meteorol. Soc. 2001, 127, 209-231. [CrossRef]

29. Seaman, R.; Bourke, W.; Steinle, P.; Hart, T.; Embery, G.; Naughton, M.; Rikus, L. Evolution of the Bureau of Meteorology's Global Assimilation and Prediction System. Part 1: Analysis and initialisation. Aust. Meteor. Mag. 1995, 44, 1-18. 
30. Bourke, W.; Hart, T.; Steinle, P.; Seaman, R.; Embery, G.; Naughton, M.; Rikus, L. Evolution of the Bureau of Meteorology's Global Assimilation and Prediction System. Part 2: Resolution enhancements and case studies. Aust. Meteor. Mag. 1995, 44, 19-40.

31. Seaman, R.S. Which Australian rawinsonde stations most influence wind analysis? Aust. Meteorol. Mag. 2007, 56, 285-289.

32. Seaman, R.S. Monitoring a data assimilation system for the impact of observations. Aust. Meteorol. Mag. 1994, 43, 41-48. article distributed under the terms and conditions of the Creative Commons Attribution (CC BY) license (http://creativecommons.org/licenses/by/4.0/). 